\title{
Living with Social Anguish: Shame and Guilt in Lung Cancer Patients
}

\author{
C. Berterö*
}

\begin{abstract}
Division of Nursing Science, Department of Medicine and Health Sciences, Faculty of Health Sciences, Linköping University, Linköping, Sweden
\end{abstract}

\begin{abstract}
Lung cancer is a disease with many biomedical and psychological symptoms. Being diagnosed with an inoperable lung cancer gives few possibilities of being cured. Prognosis remains poor even though treatment has been improved. When cure is not attainable the aim will be on palliative treatment; relieving symptoms and supplying good quality care. The different caring activities are to be evaluated in terms of the patients' own experiences and estimation of his/her quality of life. Twenty-three Swedish patients diagnosed with an inoperable lung cancer were interviewed and their live experiences were articulated. Data were interpreted through interpretive phenomenology. In this original work, six themes were identified. The present study further delves into one of these themes, namely, shame and guilt. The purpose of this study is by a secondary analysis in focus to describe and illuminate how the lung cancer diagnosis and its treatment affect the patients' quality of life. The patients try to live as usual but with social anguish. Lung cancer is strongly associated with smoking and feeling of guilt and shame are connected to this diagnosis. There is stigma due to their diagnosis. The health care system and society seem to send signals about that lung cancer is a self-induced cancer.

Patients with lung cancer expressed stigmatisation with important consequences for their quality of life. Clinical and educational interventions are needed regarding how to proper approach and care for and about these patients without adding the stigma experienced by the patients.
\end{abstract}

Key Words: Shame and guilt, social anguish, interpretive phenomenology, secondary analysis, lung cancer, smoking.

\section{INTRODUCTION}

Lung cancer is the most common malignant disease worldwide and is also the most common cause of cancer related death in males and the figures are also increasing in females $[1,2]$. The occurrence of lung cancer has increased rapidly and today it accounts for an estimate of approximately 900000 new cases each year in men and 330000 in women worldwide [1]. The cause and risk factors for lung cancer are exposure to smoking, secondary smoke, asbestos, radioactive gases such as radon and air pollution e.g. coalburning heaters [1]. Lung cancer is a disease with many biomedical and psychological symptoms [3,4], and there are few possibilities of being cured, especially with regard to inoperable lung cancer. Early stage tumours are treated by surgical resection, if possible. Those patients deemed medically unfit for surgery and/or in a more advanced stage disease are regarded as inoperable and the overall survival from lung cancer is poor; five-year relative survival barely exceeding $10 \%$ [1]. Management of patients with inoperable disease is directed at relieving local or systemic symptoms. These treatments include radiotherapy, chemotherapy and palliative systemic therapy. Prognosis remains poor even though treatment has been improved [5]. When cure is not attainable, the aim will be palliative treatment relieving symptoms and supplying good quality care. It is important

\footnotetext{
*Address correspondence to this author at the Department of Medicine and Health Sciences, Division of Nursing Science, Faculty of Health Sciences, Linköping University, SE- 58185 Linköping, Sweden; Tel: +46 13 227768;
} Fax: +46 13 123285; E-mail: carina.bertero@liu.se that the side-effects of the treatment will not exceed the desired outcomes of it and affect quality of life negatively [6].

Quality of life is complex and includes a variety of personal values and the definition of quality of life often includes physical, psychological, social and spiritual aspects of function and well-being [7]. Cooley [8] suggests that quality of life is a subjective experience and a multidimensional construction with four main dimensions related to health; functional status, physical symptoms, emotional and social functions. Functional status means that the person is able to perform his daily activities; being able to perform basic activities such as eating, dressing, managing personal hygiene walking etc. Functional status is also about that the person manages to perform activities inside as well as outside home such as cooking, cleaning, shopping, managing work etc. Physical symptoms include symptoms related to the disease or its treatment. Emotional function includes conditions with either negative or positive emotional feelings. The most studied areas of emotional function in cancer patients are anxiety and depression. Social function means that the person has the ability to retain a relationship with family and friends. Social support services recommend that there should be an agreement among all health and social care services to ensure that the needs of cancer patients are met. In order to maintain their social network, cancer patients need support [9].

Quality of life is usually described as a multidimensional and individual concept, which is difficult to measure [10] and Ferrans [11] described quality of life as a person's sense of well-being that stems from satisfaction or dissatisfaction 
with the areas of life that are important to him/her. This description is grounded in biomedical and behavioural science categories, including normal life, achievement of personal goals, social utility, natural capacity and happiness/satisfaction.

A lung cancer diagnosis affects normal life, social utility and happiness. Individuals who are diagnosed with lung cancer may experience stigmatisation. Stigma can lead to feelings of shame and guilt. It may increase the stress associated with a cancer disease and contribute to psychological and social morbidity [12]. Stigma may also threaten personal identity, social life and can seriously affect families and significant others $[13,14]$. Those suffering from stigmatising diseases such as lung cancer are forced to fight both health threats and social stigma or sickness-induced shame [15]. Shame and guilt are what we often call self-conscious emotions [16]. Are these emotions the same or differs shame from guilt? Shame is a social emotion and shame is distinctively related to the entire self. Guilt is a personal emotion and guilt is tied to some specific behaviour [17]. Shame is caused by external sanctions coming from other people or institutions, whereas guilt is caused by internal sanction [18]. Research suggests that persons may experience shame or guilt if being diagnosed with a discrediting condition such as coronary heart disease or lung cancer $[19,20]$. There are few studies focusing on patients own experiences of having a cancer diagnosis and how feelings of shame and guilt further on affect their quality of life.

The purpose of this study is by a secondary analysis performed on all data with this specific theme shame and guilt in focus to describe and illuminate how the lung cancer diagnosis and its treatment affect the patients' quality of life.

\section{METHODS AND MATERIAL}

In the original study, an Interpretive Phenomenological approach influenced by Heidegger [21] was used, in an attempt to understand the lived experience described by the persons diagnosed with an inoperable lung cancer. As human beings, we are living in the world and are a part of it; we are 'being' in the world. We express, interpret and understand our world by putting our experiences into words [21, 22]. Interpretation is the way in which understanding 'develops itself'. To interpret is to understand something [21, 22].

In phenomenological research, the question grows out of an intense interest in a specific topic and will to be gaining a deeper understanding of human beings experiences. Within oncology, phenomenological approaches have been used to gain deeper understanding of patients' altered sexual pattern, changed self-concept and patients communication needs [2324].

Purposeful sampling was used, selecting patients for participation based on their particular knowledge of a phenomenon, living with a diagnosis of inoperable lung cancer, for the purpose of sharing that knowledge [25].

Approval from the Committee on Research Ethics was obtained (Reg. no. 02-191). An enquiry about participation in the interview study was given to the patients by the nurses in conjunction with the physician responsible at the lung reception at the hospitals. In this way, both oral and written information about the study was given to the patients. The patients were informed about confidentiality, how they were selected and the aim of the study. Signed informed consent was required prior to participation.

There were persons with inoperable lung cancer from two different hospitals in Southern Sweden. Selection criteria were that the patients should; (i) being an adult, i.e. older than 18 years of age (ii) being diagnosed with an inoperable lung cancer, and an enquiry if the patient wished to participate in the study six to seven weeks after diagnosis (iii) the patient should be in palliative treatment; chemotherapy or/and radiation therapy (iiii) and be willing to share his/her lived experiences with us.

Totally, 23 patients were approached and 23 accepted to participate. The characteristics of the patients participating in the present study were: 12 men and 11 women, and they were aged between 36 and 86 years (median 67 years). Seventeen out of 23 patients were married, four were single or divorced and 2 were widow/widower. Twenty out of 23 patients had children. Among these 23 patients, five were smokers, four had stopped smoking several years ago, and 14 were non smokers.

\section{DATA COLLECTION IN THE ORIGINAL STUDY}

Data were collected using individual qualitative interviews and was performed with the same interviewer; a skilled nurse not being in the treatment situation with the patient. Before the interview, there was some small talk to establish a more intimate relationship afterwards there was talk about and reflection upon the interview. The interviews were conducted at a place convenient to the patients. Some interviews were conducted at the patients' homes, and some in a special room at the hospital. The interviews varied in length between 40 and 100 minutes, were audio-taped and transcribed verbatim.

A general interview guide approach was used [25]. A guiding question, which each informant was asked is: Tell me about your live experiences when being diagnosed with lung cancer and how this affects your life situation and quality of life. Topics related to the interview guide were raised spontaneously by the interviewer or the interviewee, and probe questions were asked to give the patient opportunities to elaborate and give examples of more general statements.

\section{DATA ANALYSIS}

In this process, the spoken language comes to stand as text [21, 22]. Cohen et al., [26] and Moustakas [27] phenomenological hermeneutic approach was used for analysis. This form of interpretation is descriptions, which in a way capture and mediate the lived experience from the patient. The analysis is performed in five steps:

(1) Every transcript was read and re-read and reflections were made upon meaning units. Meaning units are the characteristics found from the phenomenon under study.

(2) Each interview was read and re-read and data concerning the "lived experience" as a person diagnosed with lung cancer were underlined. The transcripts were analysed aiming to recognise patterns; presenting the "whole" of data. 
(3) The meaning units for each informant were described by statements. All meaning units identified as having equivalent meaning were grouped into a theme. A description and interpretation of each theme is written. This was carried out for every single interview, over and over again. The statements under each theme were described in individual textural descriptions of the experience.

(4) From the individual textural description, a common textural-structural description, a so-called composite description was developed for each theme. This describes the meaning of the theme, representing the group as a whole.

(5) From the composite description of six themes; experience of uncertainty, experience of hope, network as support, thoughts of death, feeling shame and guilt and next of kin reactions, a major theme, the essence was constructed, giving the meaning and essence of the experience; Living as usual [28]. The essence was representative of the group as a whole [26, 27].

One theme identified that seemed to have a great impact on the patients' quality of life, as well as the essence; was shame and guilt. A secondary analysis [29] was performed on all data with this specific theme in focus. Once more the raw data were analysed and interpreted with interpretive phenomenology, following the steps described above. In secondary analysis the fit between available data and the "new research question" is a most important issue to resolve [29]. In this secondary analysis study, the research question fit well with that of the original study. Both studies were concerned with the experience of being diagnosed with an inoperable lung cancer and how it affects quality of life, hence focus now was on shame and guilt.

\section{FINDINGS}

The analysis and interpretation from this secondary analysis focusing on shame and guilt in the statements in the transcribed interviews identified two themes Shame and Guilt, by interrelation of the themes the essence became to; living with social anguish

\section{Shame}

Shame is something powerful that assault on the self and is associated with efforts avoiding negative feelings and with withdrawal behaviours, i.e. shame is a social emotion.

The patients experienced a strong feeling of shame connected with this lung cancer diagnosis and sometimes the patients thought that even their next of kin would be stigmatised if people around knew about the lung cancer diagnosis.

"I do not think that I have the obligation to inform everybody about what kind of disease I have... I think that it is my affair... my and my family's affair" (I: 8).

The patients meant that talking to friends or even next of kin about having a cancer diagnosis could be allowed, but a lung cancer diagnosis was something else, even in contacts with the health care system. It was experienced as the institutions judged them as lung cancer patients.
"...I can get a better treatment if I say that I am a cancer patient (not lung cancer patient)...it is about sympathy, when visiting the health care system " (I: 2).

Lung cancer is strongly associated with smoking, and feeling of guilt and shame are connected to this diagnosis; as if all these patients are smokers. There are no considerations if these patients stopped smoking years ago, passive smoking, or had never smoked.

"Well..., especially lung cancer...it has always...I shall not say always but mostly it is associated with... smokers...I have never ever smoked... ..." (I: 6).

\section{Guilt}

The patients expressed feelings of guilt that they had caused the disease, and they were to blame themselves. Others were blaming themselves for not seeking help; waiting for their symptoms to disappear. Guilt is a personal emotion but also an action emotion. It stems from doing something we know is wrong.

“...I have been a smoker for 30 years I could read between the lines when I was talking to the doctor...well, you know... " (I: 7).

It was an obvious signal to the patient about doing something wrong. It was an attitude from an authority fortifying shame, but the action performed by the patient was personal and wrong, causing feelings of guilt.

Even when the patient did not do anything wrong, they had feelings of guilt, since it is so strongly related to wrong actions.

"Why did I get it??... If I had been a big smoker... then I had myself to blame... but I had never smoked...it is unfair" (I: 6).

\section{Social Anguish}

Social anguish is about how the patients experience distress both in body and mind and this distress have consequences for their interaction with other human beings.

The patients try to live as usual but with social anguish. There is stigma due to their diagnosis. The health care system, society and people around seem to send signals about that lung cancer is a self-induced cancer.

“...I am feeling guilt and anguish... my family tries to encourage me, but I withdraw... in some way it is dirty to be sick (in lung cancer)..." (I: 18).

Relationships with friends were hard to maintain, since they did not want them to understand what kind of cancer diagnosis they had. They tried to cover up their symptoms and other bodily changes. The cancer disease did decrease social life. An attempt to handle the situation was by withdrawing from other people, which worsen their sense of isolation.

"...my wife, it is important that she has her activities...relatives...I think it is even harder for the relatives with this kind of isolation..." (I: 20).

Several of the participants meant that if nobody asked, they did not tell about their disease, since the diagnosis was 
attitudinal connected to smoking and bad habits. The patients tried to handle their bad feelings and live as usual. There is interplay between the patient, the family and sometimes friends. They know that there is emotional distress and sorrow, but they avoid the issue and keep on living as usual.

"We live as usual...probably it is due to us using blinders...we will manage...continue our lives" (I: 22).

\section{DISCUSSION}

Research approaches such as the one used in the present study, Heidegger's interpretive phenomenology, encourage the voicing of patients' experiences and emphasises understanding of the phenomenon, an understanding of the real world of these patients expressed in their own words [21, 22, 26]. Using a secondary analysis [29] to deepen our understanding for a certain theme emphasises the understanding for this specific phenomenon under study.

The patients expressed feelings of shame and also gave examples of how this shame was fortified by institutions such as the health care system and this is in agreement with what Walbott and Scherer [18] states. This is also fortified by that the patients meant that they were stigmatised since they had a stigmatising disease, such as lung cancer, this has conformity to Waxler's [15] writing about labelling perspective on illness and medical practice. Another interesting aspect is that the patients gave examples of how they were less likely to maintain benefits of sick role status; they could tell people around that they had a cancer diagnosis, but not a lung cancer diagnosis. This judging perspective is in agreement with the statements of Chrisman [30], about ambiguous or chronic health problems.

Guilt and shame may have negative effect by causing anger, self-blame or depression [31]. The patients in the present study blamed themselves for not seeking help earlier, or just waiting for the symptoms to disappear. They also felt guilt if they had been smokers. Some of the patients had feelings of guilt towards their family, since they felt that they had caused the family members worries and perhaps damages in health.

The patients in this study expressed feelings of shame and guilt, which affects social life. Since, the lung cancer diagnosis was attitudinally connected to smoking and bad habits; several of the informants choose to avoid telling friends and others about their diagnosis. They tried to escape their bad feelings and continue as normal, and wanted to be treated as usual. This is in accordance with the study by Gray et al., [32] about men with prostate cancer. Furthermore, Yardly et al's., [33] study of lung cancer patients gives examples of not telling family members or friends, since they do not want to worry them or it is not their business.

The participants expressed a feeling of shame and guilt, which lead to social anguish. However, they tried to maintaining a normal life; living as usual was confirmed in the study by Gray et al., [32]. The stigma attached to lung cancer may have serious effect on the patients' lives. Social life with friends and families may suffer and also hinder the possibilities to get support. There will be obstacles to maintain their social network and get support [9].
The experience of stigma in lung cancer is shaped by the connection between smoking and the disease. Lung cancer is seen as self-inflicted and deserved. Often people avoid contact with a person with lung cancer [20]. Patients with lung cancer expressed stigmatisation with important consequences for their quality of life.

\section{CONCLUSION AND PERSPECTIVE}

The findings in this study points out the importance of understanding the profound effects of shame and guilt and how it affects people with discrediting diseases such as lung cancer. Shame and guilt lead to social anguish, which in turn had obvious negative effects on quality of life. The participant felt stigmatised, due to personal vs. social emotions. A better understanding of how patients with this condition experience shame and guilt may foster an improved clinical management. One could question whether shame and guilt and social anguish is unique to lung cancer patients and whether these issues have broader application. Probably, these issues could be found in other diseases such as HIV/AIDS, heart diseases and other diseases related to life style. However, it could perhaps be found in all cancer diagnosis.

Clinical and educational interventions are needed regarding how to proper approach, and care for and about these patients without adding the stigma experienced by the patients. The role of nurses shaping the agenda of supportive and palliative care is important, whereas the nurses provide treatment and care that takes into consideration the patient's individual needs and preferences. These needs are not only physical, but psychological as well as social distress.

\section{ACKNOWLEDGEMENTS}

I would like to thank all patients who participated in the interviews; sharing their experiences with me. I am also grateful to the Medical Research Council of Southeast Sweden (FORSS) for making this study feasible through financial support.

\section{REFERENCES}

[1] WHO. Stewart BW, Kleihues P, Eds. World Cancer Report. Lyon, France: IARC Press 2003; pp. 182-187.

[2] The National Board of Health and Welfare (Socialstyrelsen). Cancer Incidence in Sweden 2002. Health and Diseases. The National Board of Health and Welfare. Stockholm, Sweden: Centre for Epidemiology. Official Statistics of Sweden 2005.

[3] Colley ME. Symptoms in adults with lung cancer: a systematic research review. J Pain Symptom Manag 2000; 19(2): 137-153.

[4] Carlsen K, Bonde Jensen A, Jacobsen E, Krasnik M, Johansen C. Psychosocial aspects of lung cancer. Lung Cancer 2005; 47(3): 293-300.

[5] Napier M, Srinivasan R. Disease-Modifying Treatments in Palliative Care. In: Penson J, Fisher RA, Eds. Palliative Care for People with Cancer. $3^{\text {rd }}$ ed. London, UK: Arnold; 2002; pp. 154-167.

[6] Sörenson S. National Treatment Program for Lung cancer. (in Swedish) [online] 2007 Feb 12. Available from http://www.roe.se

[7] Muldon MF, Barger SD, Flory JD, Manuck SB. What are qualityof-life measurement measuring? BMJ 1998; 316(7130): 542-545.

[8] Cooley MM. Quality of life in persons with non-small cell lung cancer: A concept analysis. Cancer Nurs 1998; 21(3): 151-161.

[9] National Institute for Clinical Excellence: Guidance on Cancer Services. Improving Supportive and Palliative Care for Adults with Cancer-the Manual. London, UK 2008 Aug 6 Available from http://www.nice.org.uk/pdf/csgspmanual.pdf. 
[10] Ferrans CE. Development of quality of life index for patients with cancer. Onc Nurs Forum 1990; 17 (Suppl 3): 15-9.

[11] Ferrans CE. Quality of life: conceptual issues. Sem Onc Nurs 1990; 6(4): 248-54.

[12] Goffman WS. Interactionism, and the management of stigma in everyday life. In: Scambler G, Ed. Sociological theory and medical sociology. London, UK: Tavistock 1987.

[13] Ablon J. The name of stigma and medical conditions. Epilepsy Behav 2002; 3(Suppl 2): S2-S9.

[14] Fif B, Wright E. The dimensionality of stigma: a comparison of its impact on the self of persons with HIV/Aids and cancer. J Health Soc Behav 2000; 41(4): 50-67.

[15] Waxler N. The social labelling perspective on illness and medical practice. In: Eisenberg L, Kleinman A, Eds. The Relevance of Social Science for Medicine. Boston, USA: Reidel 1980; pp. 283-306.

[16] Fisher KW, Tangney JP. Self-conscious emotions and the affect revolutions. Framework and overview. In: Tangney JP, Fisher KW, Eds. Self-conscious emotions. New York, USA: The Guilford Press, 1995; pp. 3-22.

[17] Teroni F, Deconna JA. Differentiating shame from guilt. Conscious Cogn 2008; 17(3): 725-40.

[18] Walbott HG, Scherer K.R. Cultural determinants in experiencing shame and guilt. In: Tangney JP, Fisher KW, Eds. Self-conscious emotions. New York, USA: The Guilford Press 1995; pp. 465-87.

[19] Richards H, Reid M, Watt G. Victim-blaming revisited: a qualitative study of beliefs about illness causation, and responses to chest pain. Fam Pract 2003; 20(6): 711-6.

[20] Chapple A, Ziebland S, McPherson A. Stigma, shame, and blame experienced by patients with lung cancer: qualitative study. BMJ 2004; 328(7454): 1470-4.
[21] Heidegger M. (Transl. by Macquarrie \& Robinsson). Being and Time. Oxford, UK: Blackwell Publishers Ltd 1962/1997.

[22] Munhall S. Heidegger and Being and Time. London, UK: Routledge 1996.

[23] Berterö C. 2001. Altered Sexual Pattern after treatment for prostate cancer. Cancer Pract 2001; 9 (5): 245 -51.

[24] Kvåle K. Do cancer patients always want to talk about difficult emotions? A qualitative study of cancer inpatients communication needs. Eur J Oncol Nurs 2007; 11(4): 320-7.

[25] Kvale S. Interviews an introduction to qualitative research interviewing. London, UK: Sage Publications Ltd 1996.

[26] Cohen MZ, Kahn DL, Steeves RH. Hermeneutic Phenomenological Research. London, UK: Saga Publications, Inc. 2000.

[27] Moustakas C. Phenomenological Research Methods. London, UK: Sage Publications Ltd 1994.

[28] Berterö C, Vanhanen M, Appelin G. Receiving a diagnosis of inoperable lung cancer: Patients perspectives of how it affects their life situation and quality of life. Acta Oncol 2008; 47(5): 862-99.

[29] Heaton J. Reworking Qualitative Data. London, UK; Sage Publications Ltd 2004.

[30] Chrisman N. The health seeking process: an approach to the natural history of illness. Cult Med Psychiatry 1980; 1(4): 351-77.

[31] Pichert JW, Elam P. Guilt and shame in therapeutic relationships. Pat Educ Counsel 1986; 8(4): 359-65.

[32] Gray RE, Fitch M, Phillips C, Labrecque M, Fergus K. To tell or not to tell: Patterns of disclosure among men with prostate cancer. Psychooncology 2000; 9(4): 273-82.

[33] Yardley SJ, Davis CL, Sheldon F. Receiving a diagnosis of lung cancer: patients' interpretations, perceptions and perspectives. Palliat Med 2001; 15(5): 379-86.

(C) C. Berterö; Licensee Bentham Open.

This is an open access article licensed under the terms of the Creative Commons Attribution Non-Commercial License (http://creativecommons.org/licenses/ by-nc/3.0/) which permits unrestricted, non-commercial use, distribution and reproduction in any medium, provided the work is properly cited. 